\title{
Stark broadening parameters in singly and doubly ionized fluorine spectra
}

\author{
A. Srećković ${ }^{1,2}$, S. Bukvić ${ }^{1,2}$, S. Djeniže ${ }^{1,2}$, and M. S. Dimitrijević ${ }^{2,3}$ \\ ${ }^{1}$ Faculty of Physics, University of Belgrade, 11001 Belgrade, PO Box 368, Serbia \\ 2 Isaac Newton Institute of Chile, Yugoslavia Branch, Belgrade, Serbia \\ 3 Astronomical Observatory, 11160 Belgrade, Volgina 7, Serbia \\ e-mail: steva@ff.bg.ac.yu
}

Received 22 November 2003 / Accepted 1 March 2004

\begin{abstract}
Stark widths $(W)$ and shifts $(d)$ of 5 singly ionized fluorine (F II) spectral lines within the $3 s-3 p, 3 s^{\prime}-3 p^{\prime}$ and $3 d-4 f$ transitions and 5 doubly ionized fluorine (F III) spectral lines within the $3 \mathrm{~s}-3 \mathrm{p}$ transition have been measured in a linear, lowpressure, pulsed arc discharge created in $S F_{6}$ plasma at 30 400-33600 K electron temperatures and at $(2.75-2.80) \times 10^{23} \mathrm{~m}^{-3}$ electron densities. For Stark parameters of two F II and five F III lines there are no other experimental data. The widths and shifts have also been calculated using the semiclassical perturbation formalism (SCPF) (taking into account the impurity of energy levels, i.e. that the atomic energy levels are expressed as a mix of different configurations due to the configuration interaction). Calculations have been performed for temperatures between $5000 \mathrm{~K}$ and $100000 \mathrm{~K}$ for the F II spectral lines and between $10000 \mathrm{~K}$ and $300000 \mathrm{~K}$ for the F III spectral lines for electrons, protons and helium ions as perturbers. Our measured and theoretical Stark parameters are compared with existing experimental and theoretical data. Tolerable agreement was found among them.
\end{abstract}

Key words. lines: profiles - atomic data

\section{Introduction}

Atomic data, such a Stark widths $(W)$ and shifts $(d)$ are useful for plasma diagnostic purposes in a wide range of electron temperatures $(T)$ for astrophysical and laboratory plasmas. In the last five years fluorine spectral lines have become important for abundance investigations in various astrophysical plasmas (Lodders 2003; Zhu et al. 2002; Highberger et al. 2001). Only four experiments (Platiša et al. 1977; Purić et al. 1988; Djeniže et al. 1991; Blagojević et al. 1999; see also Lesage \& Fuhr 1999; Konjević et al. 2002, and references therein), deal with investigations of Stark broadening parameters $(W, d)$ of singly ionized fluorine spectral lines. A number of calculations of the Stark parameters, related to the F II, F III spectral lines, on the basis of different theoretical approaches is presented in the literature (Griem 1974; Hey 1976; Hey \& Breger 1981; Dimitrijević \& Konjević 1981; Dimitrijević 1988a,b). Furthermore, in Djeniže (2000), on the basis of regularities within an isonuclear sequence, Stark widths of F II $402.50 \mathrm{~nm}$ spectral lines (3s-3p transition) are predicted. In Djeniže et al. (1999) regularities of Stark widths of several F II spectral lines within the same transition $\left(3 s^{\prime}-3 p^{\prime}\right)$ are presented.

Send offprint requests to: M. S. Dimitrijević, e-mail: mdimitrijevic@aob.bg.ac.yu
The aim of this work is to present measured Stark FWHM (full-width at half intensity maximum, $W$ ) and shift $(d)$ values at (30400-33600) $\mathrm{K}$ electron temperatures and at $(2.75-2.80) \times 10^{23} \mathrm{~m}^{-3}$ electron densities for $5 \mathrm{~F}$ II spectral lines belonging to the $3 s-3 p, 3 s^{\prime}-3 p^{\prime}$, and $3 d-4 f$ transitions and 5 doubly ionized fluorine (F III) spectral lines within the $3 s{ }^{4} \mathrm{P}-3 \mathrm{p}{ }^{4} \mathrm{D}^{\circ}$ transition together with their calculated values using the semiclassical perturbation formalism (SCPF) updated several times (Sahal-Bréchot 1969a,b, 1974, 1991; Fleurier et al. 1977; Dimitrijević \& Sahal-Bréchot 1984, 1996b, see also a review in Dimitrijević 1996). A unique exception is the transition 3p-3d from the F II spectrum (multiplet No. 3) for which only calculated values are presented. Our measured and calculated Stark parameters are compared with the existing experimental and theoretical data (Griem 1974; Platiša et al. 1977; Dimitrijević \& Konjević 1981; Purić et al. 1988; Djeniže et al. 1991).

\section{The experiment}

A linear pulsed arc, used as plasma source, was described in detail in our previous publications (Djeniže et al. 1992, 2002a; Srećković et al. 2001, 2003). The working gas was $S F_{6}$ at $130 \mathrm{~Pa}$ filling pressure in a flowing regime $(10 \mathrm{ml} / \mathrm{min})$. 


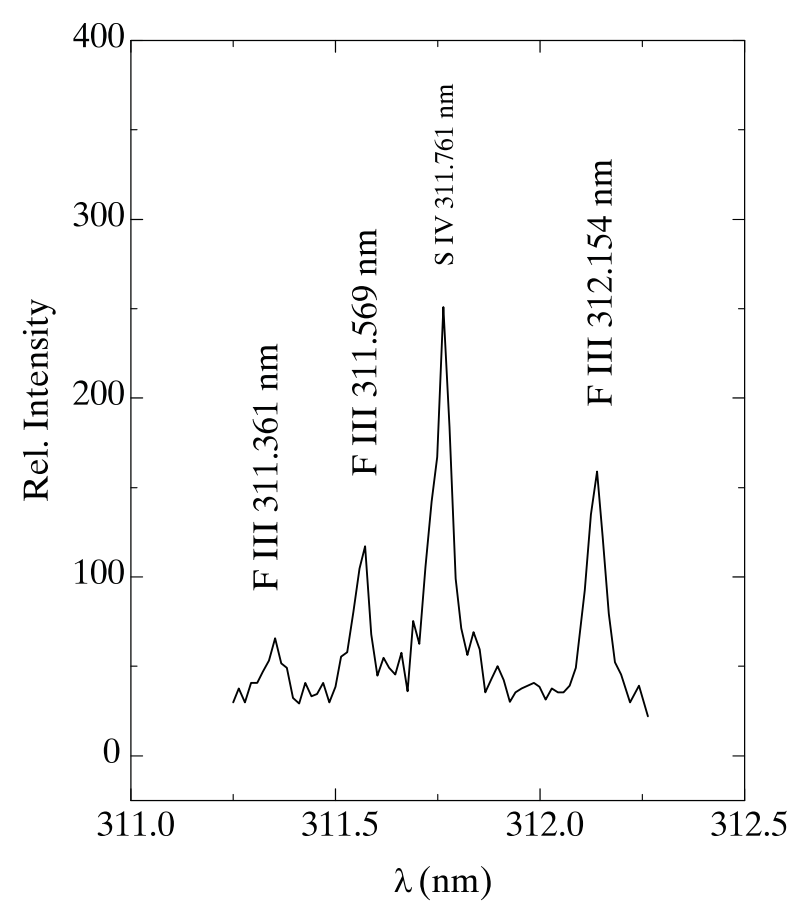

Fig. 1. Recorded spectrum with several investigated F III spectral line profiles.

The complete experimental procedure, plasma diagnostic techniques and set-up of the system used are described in Djeniže et al. (2002a). The absence of self-absorption was checked using the method described in Djeniže \& Bukvić (2001). Part of the recorded F III spectrum, is presented, as an example, in Fig. 1.

The obtained electron temperature $(T)$ and the electron density $(N)$ decays are presented in Fig. 1 of Djeniže et al. (2002b).

\section{Stark width measurements}

The measured profiles were of the Voigt type due to the convolutions of the Lorentzian Stark and Gaussian profiles caused by Doppler and instrumental broadening. For the electron density and temperature presented in our experiment, the Lorentzian fraction was dominant. Van der Waals (Griem 1974) and resonance (Griem 1974) broadening were estimated to be smaller by more than one order of magnitude in comparison to Stark, Doppler and instrumental broadening. The standard deconvolution procedure (Davies \& Vaughan 1963) has been applied using the least squares algorithm. The Stark widths were measured with $\pm 12 \%$ error at a given $N$ and $T$. Our measured Stark FWHM $\left(W_{m}\right)$ values are presented in Table 1.

\subsection{Stark shift measurements}

The Stark shifts were measured relative to the unshifted spectral lines emitted by the same plasma using a method established and applied first by Purić \& Konjević (1972). According to this method the Stark shift of a spectral line can be measured experimentally by evaluating the position of the spectral line center $\left(X_{\mathrm{C}}\right)$ recorded at different electron density values during plasma decay (Srećković et al. 2000). In principle, the method

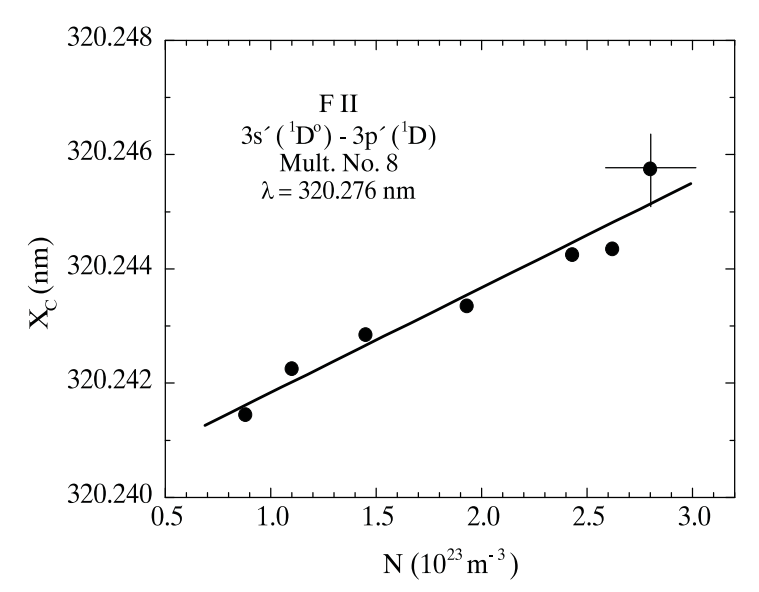

Fig. 2. The dependence of the position of the observed line center $\left(X_{\mathrm{C}}\right)$ as a function of the electron density $(N)$ during the plasma decay.

requires recording the spectral line profile at a higher electron density $\left(N_{1}\right)$ resulting in an appreciable shift and then, later, when the electron concentration has dropped to a value $\left(N_{2}\right)$ lower by at least an order of magnitude. The difference of the line center position in these two cases is $\Delta X_{\mathrm{C}}$, so that the shift $d_{1}$ at the higher electron density $N_{1}$ is

$d_{1}=N_{1} \Delta X_{\mathrm{C}} /\left(N_{2}-N_{1}\right)$.

Our Stark shift values have been obtained for line center positions corresponding to the 15 th $\mu \mathrm{s}$ and 45 th $\mu$ s after the beginning of the discharge. The dependence of the position of the observed line center $\left(X_{\mathrm{C}}\right)$ on the electron density $(N)$ during the plasma decay of the investigated $320.650 \mathrm{~nm}$ F II spectral line is presented in Fig. 2, as an example.

The Stark shift data are corrected for the electron temperature decay (Popović et al. 1992). Stark shift data are determined with $\pm 0.8 \mathrm{pm}$ error at a given $N$ and $T$. Measured $\left(d_{\mathrm{m}}\right)$ Stark shifts are presented in Table 1.

\section{Method of calculation}

The semiclassical perturbation formalism, as well as the corresponding computer code (Sahal-Bréchot 1969a,b), has been updated and optimized several times (Sahal-Bréchot 1974; Fleurier et al. 1977; Dimitrijević \& Sahal-Bréchot 1984, 1996b; Dimitrijević et al. 1991). The calculation procedure, with a discussion of updates and validity criteria, has been briefly reviewed e.g. in Dimitrijević \& Sahal-Bréchot (1996a,b) and in Dimitrijević (1996) so that only the basic details of calculations will be presented here. Stark full width $(W)$ at intensity half maximum $(F W H M)$ and shift $(d)$ of an isolated spectral line, may be expressed as (Sahal-Bréchot 1969a,b; Fleurier et al. 1977):

$$
\begin{aligned}
& W=N \int v f(v) \mathrm{d} v\left(\sum_{i^{\prime} \neq i} \sigma_{i i^{\prime}}(v)+\sum_{f^{\prime} \neq f} \sigma_{f f^{\prime}}(v)+\sigma_{\mathrm{el}}\right)+W_{\mathrm{R}} \\
& d=N \int v f(v) \mathrm{d} v \int_{R_{3}}^{R_{\mathrm{D}}} 2 \pi \rho \mathrm{d} \rho \sin 2 \phi_{\mathrm{p}}
\end{aligned}
$$


Table 1. Measured F II and F III Stark FWHM $\left(W_{\mathrm{m}}\right.$ in pm) and shift $\left(d_{\mathrm{m}}\right.$ in pm) at a given $T$ (in $\left.10^{4} \mathrm{~K}\right)$ and $N\left(\right.$ in $\left.10^{23} \mathrm{~m}^{-3}\right)$. Transitions and wavelengths $(\lambda$ in $\mathrm{nm})$ are taken from NIST (2003). Negative shift is toward the blue.

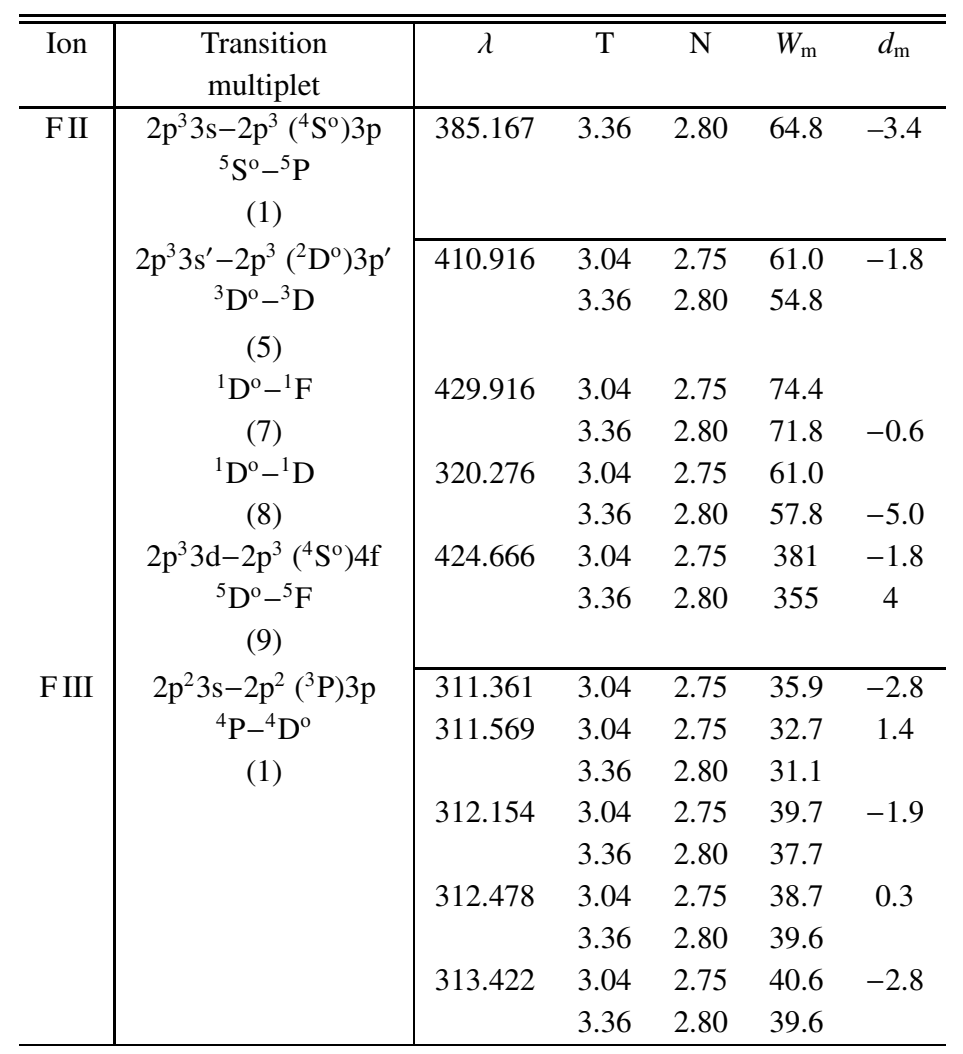

where $N$ is the electron density, $f(v)$ the Maxwellian velocity distribution function for electrons, $\rho$ denotes the impact parameter of the incoming electron, $i$ and $f$ denote the initial and final atomic energy levels, and $i^{\prime}, f^{\prime}$ their corresponding perturbing levels, while $W_{\mathrm{R}}$ gives the contribution of the Feshbach resonances (Fleurier et al. 1977). The inelastic cross section $\sigma_{j, j^{\prime}}(v)$ can be expressed by an integral over the impact parameter of the transition probability $P_{j j^{\prime}}(\rho, v)$ as

$\sum_{i^{\prime} \neq i} \sigma_{j j^{\prime}}(v)=\frac{1}{2} \pi R_{1}^{2}+\int_{R_{1}}^{R_{\mathrm{D}}} \sum_{j \neq j^{\prime}} P_{j j^{\prime}}(\rho, v), j=i, f$

and the elastic cross section is given by

$\sigma_{\mathrm{el}}=2 \pi R_{2}^{2}+\int_{R_{2}}^{R_{\mathrm{D}}} 8 \pi \rho \mathrm{d} \rho \sin ^{2} \delta$

$\delta=\left(\phi_{\mathrm{p}}^{2}+\phi_{\mathrm{q}}^{2}\right)^{1 / 2}$.

The phase shifts $\phi_{\mathrm{p}}$ and $\phi_{\mathrm{q}}$ due respectively to the polarization potential $\left(r^{-4}\right)$ and to the quadrupolar potential $\left(r^{-3}\right)$, are given in Sect. 3 of Chapter 2 in Sahal-Bréchot (1969a). $R_{\mathrm{D}}$ is the Debye radius. All the cut-offs $R_{1}, R_{2}, R_{3}$ are described in Sect. 1 of Chapter 3 in Sahal-Bréchot (1969b). The formulae for the ion-impact widths and shifts are analogous to Eqs. (1)-(3), without the resonance contribution to the width. The difference in calculation of the corresponding transition probabilities and phase shifts as functions of the impact parameter in Eqs. (2) and (3) is in the ion perturbing trajectories which are influenced by a repulsive Coulomb force instead of an attractive one as for electrons.
Atomic energy levels needed for the calculation have been taken from Bashkin \& Stoner (1975). The calculations have been performed for electron temperatures between $5000 \mathrm{~K}$ and $100000 \mathrm{~K}$ for F II spectral lines and $10000 \mathrm{~K}$ and $300000 \mathrm{~K}$ for F III spectral lines for electrons, protons and helium ions as perturbers. Calculated $W$ and $d$ values are presented in Tables 2 and 3.

\section{Results and discussion}

Our measured ( $W_{\mathrm{m}}$ and $d_{\mathrm{m}}$ ) and calculated ( $W$ and $d$ ) values at a given electron temperature $(T)$ and density $(N)$ are given in Tables 1 and 2, respectively. For each value given in Table 2, the collision volume multiplied by the perturber density is much less than one and the impact approximation is valid (Sahal-Bréchot 1969a,b). When the impact approximation is not valid, the ion broadening contribution may be estimated by using the quasistatic approach (Sahal-Bréchot 1991; or Griem 1974).

To compare the measured and calculated Stark $F W H M$ values, we have presented in Figs. 3-8 an existing experimental data set including our results, together with our (SCPF) theoretical results and those from Griem (1974) (G). In the case of F III lines the previous calculations made by Dimitrijević \& Konjević (1981) have also been included for comparison.

The F II $W$ values generated by protons and helium ions are up to 5-10 times smaller than the widths generated by electrons and show weak dependence on the temperature (see Table 2). The F II $d$ values generated by electrons, protons and helium 
Table 2. Calculated F II Stark $F W H M(W$ in pm) and shift ( $d$ in pm) values for electrons (a), protons (b) and helium ions (c) as perturbers for various plasma temperatures $\left(T\right.$ in $\left.10^{3} \mathrm{~K}\right)$ and $10^{23} \mathrm{~m}^{-3}$ perturber density. $\langle\lambda\rangle$ is the mean wavelength in the multiplet. The negative shift is toward the blue.

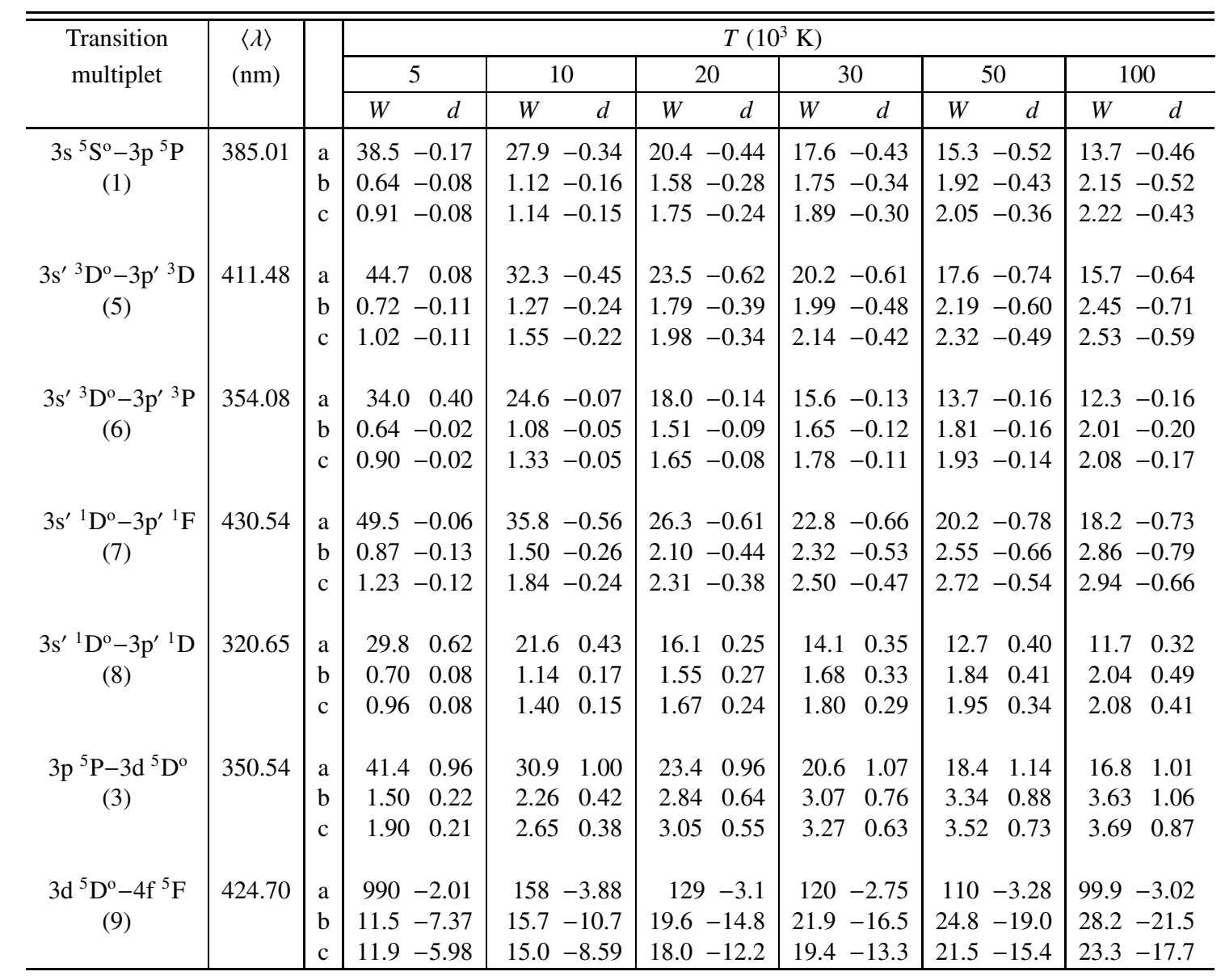

Table 3. Calculated F III Stark $F W H M(W$ in pm) and shift ( $d$ in pm) values for electrons (a), protons (b) and helium ions (c) as perturbers for various plasma temperatures $\left(T\right.$ in $10^{3} \mathrm{~K}$ ) and $10^{23} \mathrm{~m}^{-3}$ perturber density. $\langle\lambda\rangle$ represents the mean wavelength in the multiplet. Negative shift is toward the blue.

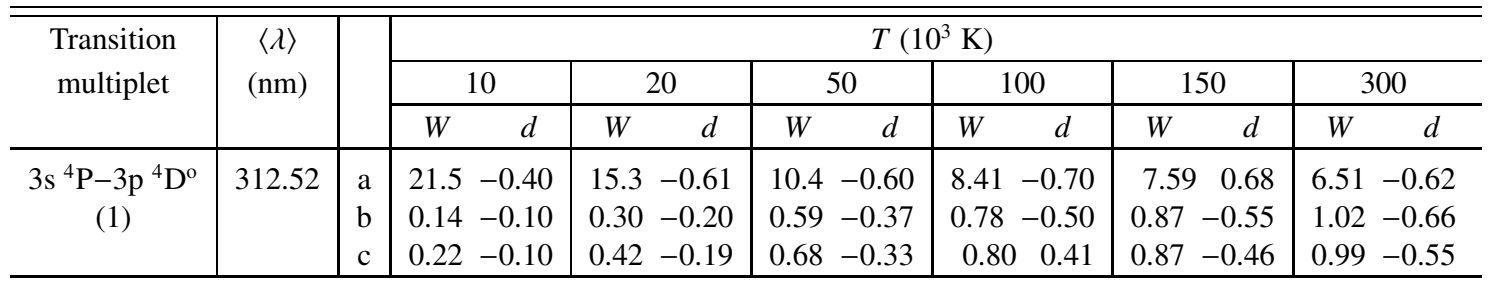

ions are very small, except for the multiplet No. 9, and are of the same magnitude. Similar conclusions can be obtained for the F III $W$ and $d$ values in the multiplet No. 1 (see Table 3).

Very good agreement has been found among our measured and calculated F II $W$ and $d$ values. Existing experimental $W$ values (Djeniže et al. 1991; Platiša et al. 1977) also agree with our calculated values (see Figs. 3 and 4). Griem's (1974) $W$ values lie below ours. In the case of the F II $d$ values our SCPF calculations provide smaller values than those predicted by Griem (1974) (see Fig. 6).

Our measured and calculated F III $W$ values agree mutually (within 5\%) and both lie above previously calculated (Dimitrijević \& Konjević 1981) and measured (Purić et al. 1988) values. Measured F III $d$ values show evident scatter and within the experimental accuracy are practically equal to zero. Our calculation provides a very small negative shift which is practically independent on the electron temperature.

On the basis of the obtained $W$ and $d$ values we can conclude that a good agreement is found between our measured and calculated (SCPF) $W$ values (within the experimental accuracy and uncertainties of the calculations) in the case of the F II lines that belong to the $3 s-3 p, 3 d-4 f$ and $3 s^{\prime}-3 p^{\prime}$ transition.

We found that the Stark width generated by electrons is dominant and that the proton and helium ion contributions to the total Stark width can be neglected up to $150000 \mathrm{~K}$. 


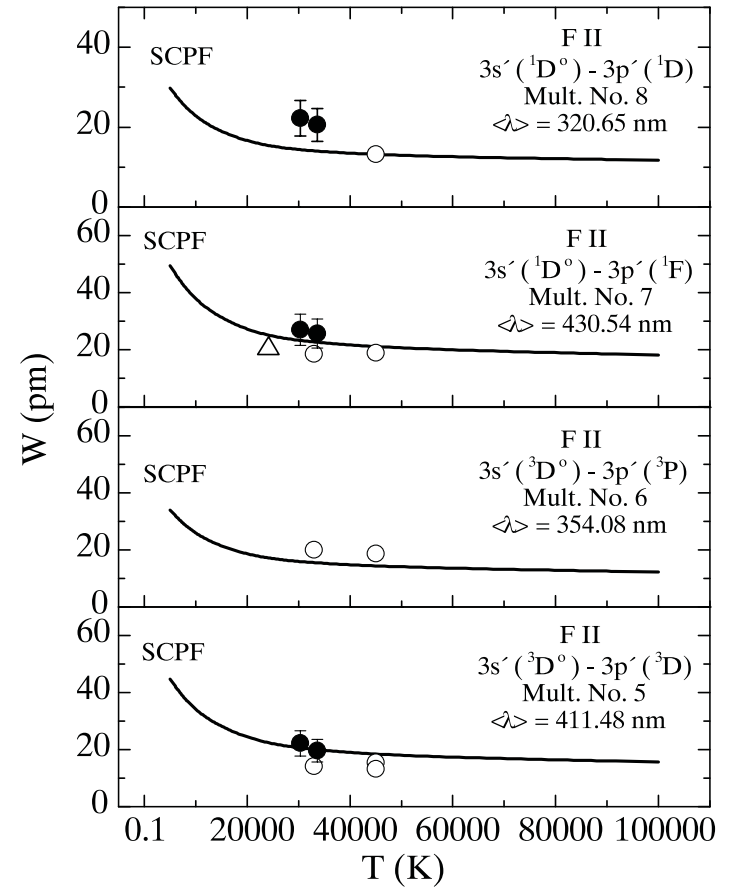

Fig. 3. F II Stark widths ( $W$ in pm) as a function of the electron temperature $(T)$ in the $3 \mathrm{~s}-3 \mathrm{p}$ transition at $10^{23} \mathrm{~m}^{-3}$ electron density. $\bullet$, our experimental results, $\Delta$, Platiša et al. (1977) and o, Djeniže et al. (1991). SCPF (full line) represents our calculations using the semiclassical perturbation formalism. Error bars include the uncertainties of the width and electron density measurements $( \pm 20 \%)$.

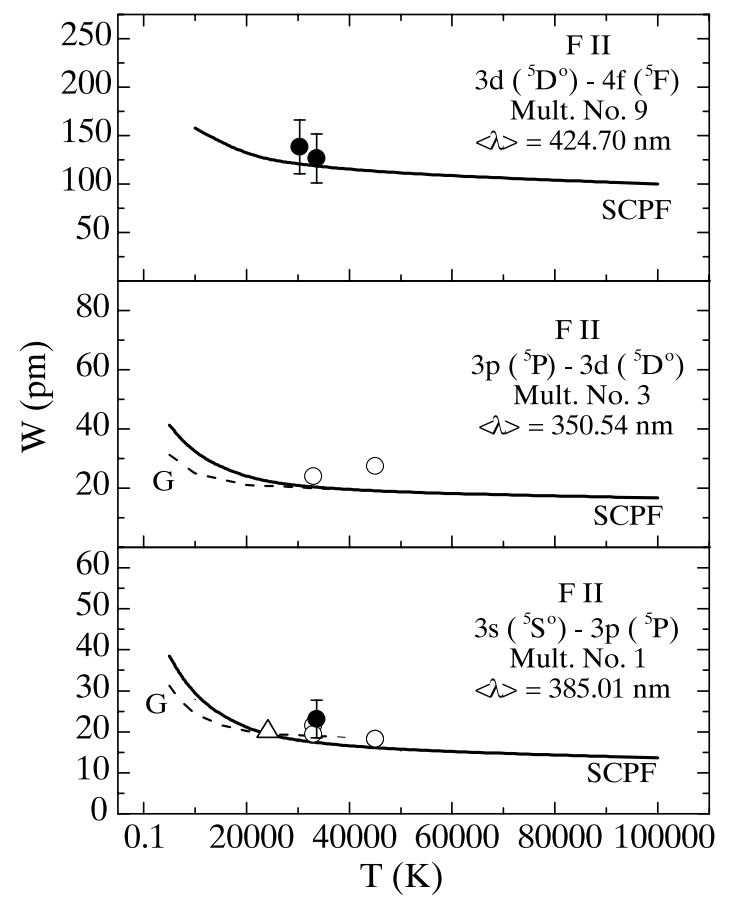

Fig. 4. F II Stark widths ( $W$ in pm) as a function of the electron temperature $(T)$ in the $3 \mathrm{~s}-3 \mathrm{p}, 3 \mathrm{p}-3 \mathrm{~d}$ and $3 \mathrm{~d}-4 \mathrm{f}$ transitions at $10^{23} \mathrm{~m}^{-3}$ electron density. •, our experimental results; $\Delta$, Platiša et al. (1977) and o, Djeniže et al. (1991). SCPF (full line) represents our calculations using the semiclassical perturbation formalism. G (dashed lines), denotes values calculated by Griem (1974). Error bars include the uncertainties of the width and electron density measurements $( \pm 20 \%)$. $\langle\lambda\rangle$ is the mean wavelength in the multiplet.

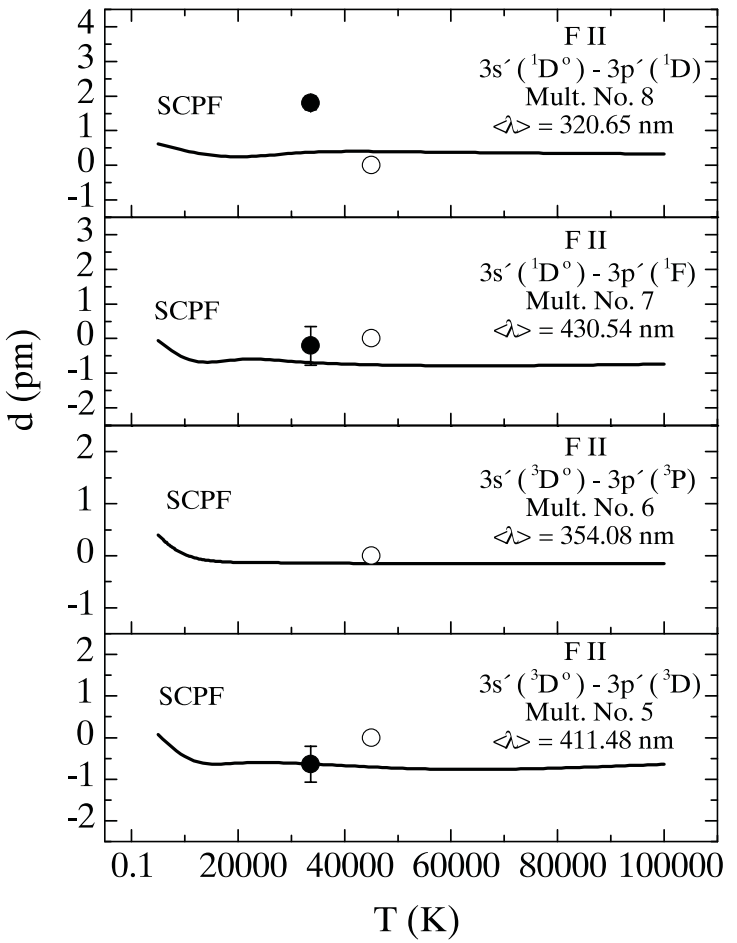

Fig. 5. F II Stark shifts ( $d$ in pm) as a function of the electron temperature $(T)$ at $10^{23} \mathrm{~m}^{-3}$ electron density. $\bullet$, our experimental results and o, results from Djeniže et al. (1991). SCPF (full line) represents our calculations using the semiclassical perturbation formalism. $\langle\lambda\rangle$ is the mean wavelength of the multiplet.

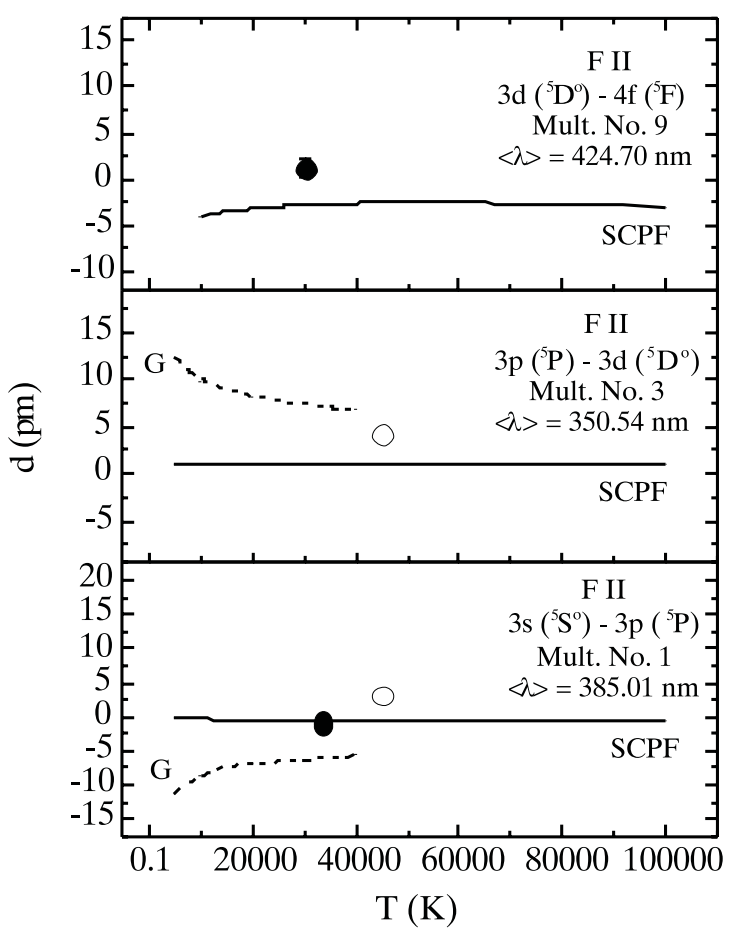

Fig. 6. F II electron Stark shifts ( $d$ in pm) as a function of the electron temperature $(T)$ in the $3 \mathrm{~s}-3 \mathrm{p}, 3 \mathrm{p}-3 \mathrm{~d}$ and $3 \mathrm{~d}-4 \mathrm{f}$ transitions at $10^{23} \mathrm{~m}^{-3}$ electron density. $\bullet$, our experimental results and $\circ$, from Djeniže et al. (1991). SCPF (full line) represents our calculations using the semiclassical perturbation formalism. G (dashed line), denotes calculations of Griem (1974). $\langle\lambda\rangle$ is the mean wavelength of the multiplet. 


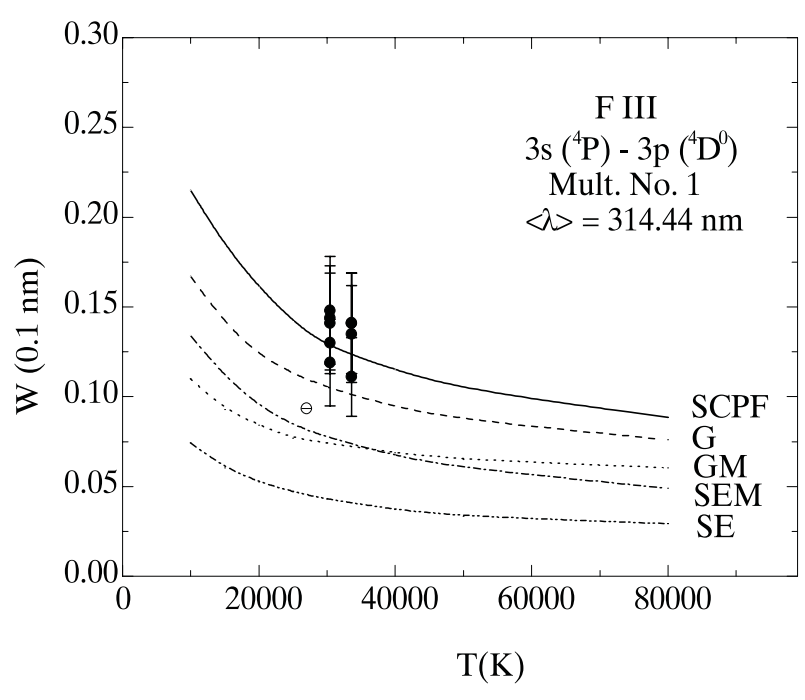

Fig. 7. F III electron Stark $F W H M$ vs. electron temperature at $10^{23} \mathrm{~m}^{-3}$ electron density. $\mathrm{G}$ represents (dashed line) results from Dimitrijević \& Konjević (1981) based on Griem's semiclassical method (see Griem 1974, Eq. (526)). GM denotes its modification by Dimitrijević \& Konjević (1980). SEM denotes the modified semiempirical method (Dimitrijević \& Konjević 1980). SE denotes the result from Griem's semiempirical calculation (Griem 1968). SCPF denotes our electron Stark width values calculated on the basis of the semiclassical perturbation formalism. $\bullet$ denotes our new experimental data and $\oslash$ denotes results from Purić et al. (1988).

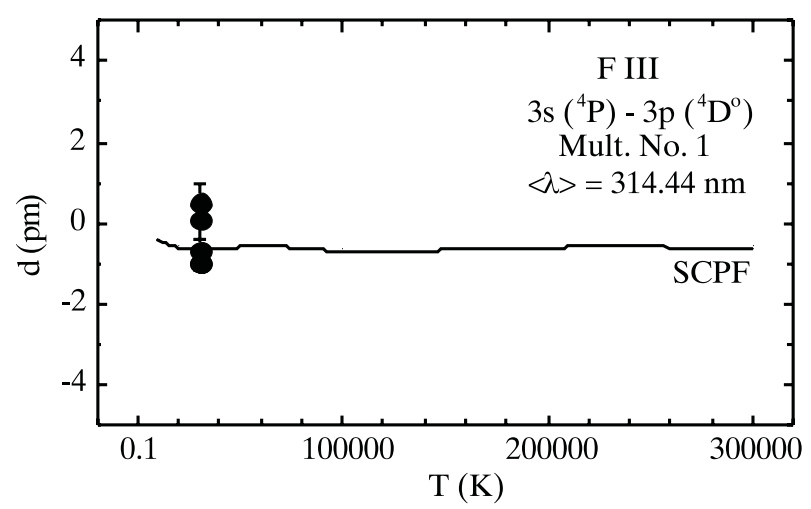

Fig. 8. F III electron Stark shift $(d)$ vs. electron temperature at $10^{23} \mathrm{~m}^{-3}$ electron density. $\bullet$ denotes our experimental data. SCPF (full line) represents our electron Stark shift values calculated on the basis of the semiclassical perturbation formalism.

Our calculated Stark shift $d$ values are generally very small $(<1 \mathrm{pm})$ with negative sign in the case of the F II lines belonging to the $3 s-3 p$ and $3 s^{\prime}-3 p^{\prime}$ transitions except for the muliplet No. 8 where the calculated $d$ values have a positive sign. Small $d$ values with positive sign are found for the $3 \mathrm{p}-3 \mathrm{~d}$ transition. In the case of the $3 \mathrm{~d}-4 \mathrm{f}$ transition the calculated $d$ values are less than $4 \mathrm{pm}$ with a negative sign.

We hope that the results presented in this paper, for Stark broadening parameters of the F II and F III spectral lines, will be of interest for a number of problems in plasma physics and astrophysics.

Acknowledgements. This work is a part of the projects "Determination of the atomic parameters on the basis of the spectral line profiles" (OI 1228) and "Influence of collision processes on astrophysical plasma line shapes" (GA 1195) supported by the Ministry of Science, Technologies and Development of the Republic of Serbia.

\section{References}

Bashkin, S., \& Stoner, J. J. Jr. 1975, Atomic Energy Levels and Grotrian Diagrams (Amsterdam: North-Holland), 1

Blagojević, B., Popović, M. V., \& Konjević, N. 1999, Phys. Scr., 59, 374

Davies, J. I., \& Vaughan, J. M. 1963, ApJ, 137, 1302

Dimitrijević, M. S. 1988a, A\&AS, 76, 53

Dimitrijević, M. S. 1988b, Bull. Astron. Belgrade, 139, 31

Dimitrijević, M. S. 1996, Zh. Prikl. Spectrosk., 63, 810

Dimitrijević, M. S., \& Konjević, N. 1980, JQSRT, 24, 541

Dimitrijević, M. S., \& Konjević, N. 1981, in Spectral Line Shapes, ed. B. Wende (New York: Walter de Gruyter, \& Co.), 1, 211

Dimitrijević, M. S., \& Sahal-Bréchot, S. 1984, JQSRT, 31, 301

Dimitrijević, M. S., \& Sahal-Bréchot, S. 1996a, A\&AS, 119, 369

Dimitrijević, M. S., \& Sahal-Bréchot, S. 1996b, Phys. Scr., 54, 50

Djeniže, S. 2000, Serb. Astron. J., 161, 15

Djeniže, S., \& Bukvić, S. 2001, A\&A, 365, 252

Djeniže, S., Labat, J., Srećković, A., et al. 1991, Phys. Scr., 44, 148

Djeniže, S., Srećković, A., \& Labat, J. 1992, A\&A, 253, 632

Djeniže, S., Srećković, A., Labat, J., \& Platiša, M. 1999, Phys. Scr., 53, 98

Djeniže, S., Srećković, A., Jelisavčić, M., \& Bukvić, S. 2002a, A\&A, 389, 1086

Djeniže, S., Dimitrijević, M. S., Srećković, A., \& Bukvić, S. 2002b, A\&A, 396, 331

Fleurier, C., Sahal-Bréchot, S., \& Chapelle, J. 1977, JQSRT, 17, 595

Griem, H. R. 1968, Phys. Rev., 165, 258

Griem, H. R. 1974, Spectral Line Broadening by Plasmas (New York: Academic Press)

Hey, J. D. 1976, JQSRT, 16, 69

Hey, J. D., \& Breger, P. 1981, in Spectral Line Shapes, ed. B. Wende (New York: Walter de Gruyter \& Co.), 1, 201

Highberger, J. L., Savage, C., Bieging, J. H., \& Ziurys, L. M. 2001, ApJ, 562, 790

NIST 2003, Atomic Spectra Data Base Lines (Wavelengths ordered), http://www.physics.nist.gov

Konjević, N., Lesage, A., Fuhr, J.R., \& Wiese, W. L. 2002, J. Phys. Chem. Ref. Data, 31, 3, 819

Lesage, A., \& Fuhr, J. R. 1999, Bibliography of Atomic Line Shapes and Shifts (April 1992 though June 1999), Observatoire de Paris

Lodders, K. 2003, ApJ, 591, 1220

Platiša, M., Dimitrijević, M. S., Popović, M. V., \& Konjević, N. 1977, A\&A, 54, 837

Popović, L. Č., Srećković, A., \& Djeniže, S. 1992, Proc. 11th ICSLS, A25, Carry de Rouet, France

Purić, J., \& Konjević, N. 1972, Z. Phys., 249, 440

Purić, J., Srećković, A., Djeniže, S., \& Platiša, M. 1988, Phys. Rev. A, $37,11,4380$

Sahal-Bréchot, S. 1969a, A\&A, 1, 91

Sahal-Bréchot, S. 1969b, A\&A, 2, 322

Sahal-Bréchot, S. 1974, A\&A, 35, 321

Sahal-Bréchot, S. 1991, A\&A, 245, 322

Srećković, A., Drinčić, V., Bukvić, S., \& Djeniže, S. 2000, J. Phys. B, 33, 4873

Srećković, A., Dimitrijević, M. S., \& Djeniže, S. 2001, A\&A, 371, 354

Srećković, A., Dimitrijević, M. S., Djeniže, S., \& Bukvić, S. 2003, A\&A, 400, 1155

Zhu, C., Krems, R., Dolgano, A., \& Balakrishnan, N. 2002, ApJ, 577, 795 